\title{
Perencanaan Arsitektur Enterprise Menggunakan TOGAF ADM (Studi Kasus:Kantor Desa Lembang)
}

\author{
Desy Angeline1, Charitas Fibriani² \\ Information System, Fakultas Teknologi Informasi, Satya Wacana Christian University, Indonesia \\ Email:1682017404@student.uksw.edu,charitas.fibriani@uksw.edu
}

\begin{abstract}
The Lembang Village Office is a government institution that operates at the Village level in the Bengkayang Regency area. The Lembang Village Government has not implemented an Information System in carrying out its duties, this can be seen from the obstacles faced by the Village government. The obstacles faced are the frequent accumulation of old data, so it is difficult when it will be recorded again, even usually there is data lost so it requires a system that can help data storage. The purpose of this research is to provide directions or directions to be able to implement an information system for data storage. performance in the future, the method used this time is TOGAF (The Open Group Architecture Framework) ADM (Architecture Development Method). This research will produce a blueprint and provide a roadmap using the elements that exist in the togaf at the Lembang Village Office in order to implement an information system on future performance.
\end{abstract}

Keywords: Enterprise Architecture, TOGAF (The Open Group Architecture Framework), Information Systems Architecture.

\section{PENDAHULUAN}

Kantor Desa Lembang Merupakan suatu tempat dimana digunakan oleh pemerintah desa terkait untuk melaksanakan kegiatan administrasi. Kegiatan administrasi yang diproses antara lain adalah pembuatan surat keterangan tidak mampu, kartu tanda penduduk, kepengurusan kartu keluarga, serta membantu proses dalam pembuatan surat pindah domisili. Desa merupakan kesatuan masyarakat hukum yang memiliki wewenang untuk mengatur dan mengurus urusan pemerintahan, hal bersangkutan dengan masyarakat setempat. Pemerintahan desa berdasarkan Peraturan Pemerintah Nomor 47 Tahun 2015 adalah penyelenggara urusan pemerintahan dan kepentingan masyarakat setempat dalam system pemerintahan Negara Kesatuan Republik Indonesia. Adapun fungsi dari pemerintah desa yaitu, hal yang bersangkutan dengan administrasi dengan masyarakat setempat yang dilakukan oleh kepala desa, perangkat desa dan warga desa itu sendiri. Penggunaan teknologi di 
Vol. 3, No. 2, June 2021

p-ISSN: 2656-5935 http://journal-isi.org/index.php/isi

e-ISSN: 2656-4882

pemerintahan Desa Lembang dirasa masih kurang mumpuni untuk mengerjakan data masyarakat hal ini dapat dilihat dari kegagalan pemerintah dalam menyalin data yang lama. Hal ini bisa tterjadi dikarenakan pemerintah juga masih belum menggunakan sistem informasi untuk proses pendataan. Perencanaan dalam menjalankan Pemerintahan Desa perlu penyegaran agar dapat berjalan dengan baik, dengan masuknya teknologi sudah seharusnya pemerintah menggunakan dan memanfaatkan teknologi sebaik mungkin, termasuk Pemerintah Desa agar mudah dalam mencari data yang sudah lama tertimbun. Penelitian kali ini akan membantu agar penerapan teknologi yang sudah ada dapat dimanfaatkan dan semaksimal mungkin digunakan untuk membantu proses administrasi Desa dan kependudukan sosial terkait pengembangan yang akan dilakukan pada Kantor Desa Lembang.

Penelitian ini bertujuan untuk memberikan saran dan rekomendasi agar Kantor Desa Lembang dapat menerapkan sistem informasi pada sistem kinerja yang dilakukan untuk pendataan masyarakat. Arsitektur sistem informasi dapat mengarahkan proses bisnis pada perusahaan sehingga sistem informasi pada perusahaan dapat memberikan perubahan pada visi dan misi yang akan dicapai. Arsitektur sistem informasi dapat menghasilkan teknologi informasi sesuai dengan kebutuhan yang akan diperlukan oleh perusahaan [1]. TOGAF merupakan salah satu metode yang memiliki manfaat dalam membangun arsitektur enterprise dan juga memiliki metodologi pengembangan design arsitektur yaitu arsitektur development method (ADM).

TOGAF ADM mempunyai beberapa siklus spesifik yang akan membantu pengembangan dan proses arsitektur teknologi informasi pada suatu instansi maupun perusahaan. TOGAF ADM memiliki 8 fase dalam proses untuk dapat membantu pengembangan sistemasi teknologi informasi yang akan berguna bagi Kantor Desa Lembang yang belum menerapkan sistem informasi pada proses kinerja yang dilakukan. Framework ini dapat membantu dan bermanfaat untuk membuat arsitektur teknologi pada masa mendatang [1].Adapun keunggulan dari framework TOGAF ADM ini dapat memberikan petunjuk dan arahan kepada perusahaan ataupun organisasi yang ingin merencanakan,merancang ,serta mengimplementasikan sistem informasi pada perusahaannya.

\section{METODE}

Metode Penelitian yang digunakan dalam pengumpulan data pada penelitian kali ini yaitu metode penelitan deskriptif kualitatif. Penelitian deskriptif kualitatif adalah metode yang bersifat cenderung menjabarkan penelitian yang apa adanya yang menggambarkan kondisi tanpa ada perlakuan atau manipulasi data pada variable yang diteliti. Pengumpulan data dilakukan dengan cara wawancara pada beberapa pihak yang bekerja pada Kantor Desa Lembang. Perolehan data yang 
Vol. 3, No. 2, June 2021

p-ISSN: 2656-5935 http://journal-isi.org/index.php/isi e-ISSN: 2656-4882

dihasilkan dengan cara wawancara akan ditranskripkan dengan catatan tertulis yang akan dianalisis sesuai dengan bidang bidangnya.

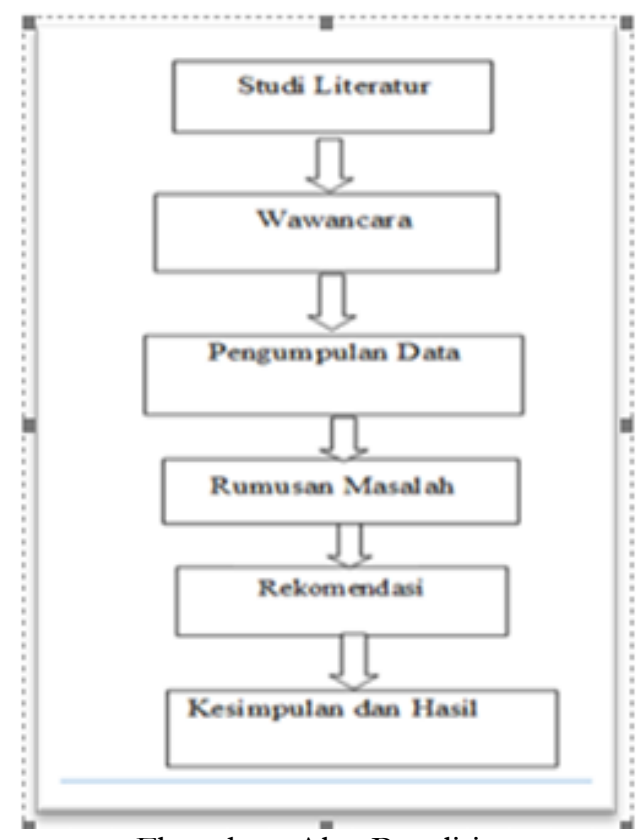

Flowchart Alur Penelitian

1. Tahap pertama, pada penelitian kali ini yaitu studi literatur dengan melakukan kajian terdahulu yang relevan dan membaca beberapa jurnal mengenai dan mendalami teori Togaf. Penelusuran dilakukan sebagai landasan mempelajari pustaka yang berkaitan dengan TOGAF Framework. Tinjauan Pustaka yaitu dilakukan untuk mencari perbedaan pada penelitian yang telah dilakukan sebelumnya yang berkaitan dengan penelitian kali ini.

2. Tahap kedua, pada penelitian kali ini adalah wawancara dengan bagian kaur ulang pada Kantor Desa Lembang guna mendapatkan data berupa kependudukan sosial, prosedur pendataan masyarakat, dan Administrasi Desa.

3. Tahap ketiga, dilakukan pengumpulan data dengan cara wawancara dengan beberapa staff yang bekerja pada Kantor Desa Lembang.Wawancara dilakukan pada staff yang berkaitan dengan penelitian yang akan dilakukan.

4. Tahap keempat, pada penelitian kali ini adalah rumusan masalah yang diperoleh dari wawancara dengan Narasumber staff bagian Daur Ulang dan Kasi Pelayanan Kantor Desa Lembang. 
Vol. 3, No. 2, June 2021

p-ISSN: 2656-5935 http://journal-isi.org/index.php/isi

e-ISSN: 2656-4882

5. Tahap kelima, pada penelitian ini adalah rekomendasi berupa cetak biru yang akan diberikan pada Kantor Desa Lembang yang menjadi objek dari penelitian ini sebagai acuan untuk memaksimalkan kinerja pada Kantor Desa untuk kedepan nya.

6. Tahap keenam, pada penelitian kali ini adalah kesimpulan hasil yang menjelaskan tahapan tahapan SI/TI pada Kantor Desa Lembang.

\subsection{Tinjauan Pustaka}

Penelitian sebelumnya yang dijadikan referensi untuk penelitian kali ini juga telah membahas mengenai perencanaan menggunakan framework togaf adm dengan judul'Perencanaan Arsitektur Enterprise Sistem Infromasi Disnaskersostrans Kabupaten Purwakarta Menggunakan Togaf ".Tujuan dari penelitian tersebut membangun sistem informasi dan teknologi informasi dengan menggunakan arsitektur enterprise yang tedapat pada togaf agar selaras dengan proses bisnis yang ada pada Disnakersostrans Kabupaten Purwakarta.Penelitian tersebut menghasilkan cetak biru berupa arsitektur bisnis ,arsitektur data ,arsitektur aplikasi yang akan akan menghasilkan 5 aplikasi lama yaitu,IPK,SIMPKH,SIMDA,SISKOTKLN dan TKA online, serta 23 aplikasi terbaru.Hasil dari dari penelitian ini juga menghasilkan arsitektur teknologi berupa jaringan sebagai acuan dalam pembangunan sistem selanjutnya ,agar dapat menunjang proses bisnis yang ada pada Disnakersostrans Kabupaten Purwakakarta[3].

Penelitian sebelumnya juga telah membahas tentang perancangan menggunakan enterprise arsitektur framework togaf dengan judul "Perancangan Enterprise Architecture Pada PT.GadingPutra Samudra Menggunakan Framework Togaf adm. Hasil dari penelitian tersebut akan berfokus pada arsitektur bisnis dan juga hasil yang diharapkan yaitu sistem informasi dan teknologi informasi pada proses bisnis dapat terintegrasi agar sejalan dan juga dapat membantu proses bisnis pada perusahaan untuk mendapatkan proses bisnis yang optimal,efektif serta efisien[4].

Penelitian selanjutnya yang akan dijadikan referensi membahas tentang keselarasan teknologi informasi untuk memenuhi kebutuhan organisasi untuk mncapai tujuan sinergitas perguruan tinggi.Tujuan dari penelitian tersebut menitikberatkan untuk pengembangan organisasi atau perguruan tinggi agar mengahsilkan cetak biru[5].Penelitian sebelumnya juga membahas mengenai arsitektur enterpise untuk menghasilkan blue print digunakan arsitektur sistem informasi dan teknologi informasi sebagai perencanaan agar aktivitas dapat berjalan secara efektif dan efisien[6].Perancangan sistem informasi menggunakan togaf untuk mendukung tata kelola teknologi informasi pada instansi maupun organisasi untuk peningkatan proses dalam bisnis[7]. Penelitian dengan judul "Perencanaan Arsitektur Enterprise Menggunakan Togaf adm versi 9 (Studi 
Kasus:Bimbel Salemba Group) yang menghasilkan cetak biru serta memberikan petunjuk (roadmap) untuk mengimplementasikan aplikasi untuk bimbel Salemba Group[8].Penelitian selanjutnya akan menghasilkan pemodelan yang akan dilakukan untuk penyesuaian pada kebutuhan bisnis untuk objek penelitiannya yaitu fitness center agar perencanaan SI/TI berjalan dengan baik[9].

Rancangan untuk pemodelan arsitektur enterprise menggunakan togaf(ADM) pada Dinas Pendidikan Provinsi Riau yang bertujuan untuk memberikan hasil penetian yang akan memberikan urusan perdebatan sistema informasi yang digunakan akan menjadi selaras[10].Arsitektur Enterprise dibutuhkan untuk pengimplementasian yang akan membantu memenuhi tujuan dan membantu visi dan misi instansi dan organisi pada masa depan dan dapat menghasilkan sistem infromasi berupa web yang dibutuhkan Gereja Jemaat Kristus Indonesia[11].Framework Zachman yang digunakan dalam penlitian sebelumnya memiliki tujuan untuk dapat memilih bagian akan digabungkan dan disusun untuk penerapan model sistem informasi akademik atau dapat menjadi acuan dalam membangun sistem informasi edukasi/akademik[12]. Penelitian kali ini akan berfokus untuk menghasilkan cetak biru berupa prosedur perencanaan yang akan menjadi pedoman utnuk alur administrasi desa pada masa mendatang menggunakan framework togaf dengan menggunakan fase yang terdapat pada togaf adm yaitu preliminary, opportunities and solutions.

\section{HASIL DAN PEMBAHASAN}

TOGAF (The Open Group Architecture Framework) merupakan suatu kerangka kerja dan pengembangan metode untuk Enterprise Architecture yang digunakan oleh arsitek perusahaan untuk merancang, merencanakan, melaksanakan, dan mengatur arsitektur perusahaan secara terperinci dan mendetail [13]. Framework togaf merupakan suatu metode yang dapat melakukan arsitektur enterprise, arsitektur enterprise adalah tool yang berguna untuk pengembangan jangkaun dari setiap arsitektur yang ada[14].Togaf telah banyak digunakan dalam berbagai macam bidang seperti perindustrian ,keuangan dan juga pendidikan[8] .Archictecture Development Method (ADM) adalah sekumpulan metode yang mempunyai aktivitas yang ada model pegembangan arsitektur enterprise didalam nya[15]

Togaf memliki beberapa fase dalam tahapan nya. Berikut fase-fase yang terdapat pada TOGAF ADM:

1. Preliminary fase

Preliminary fase merupakan tahapan persiapan dan kegiatan yang dibutuhkan untuk tecapainya tujuan bisnis arsitektur enterprise yang baru dan juga termasuk penentuan metode dan juga arsitektur enterprise, serta mendefinisikan prinsipprinsip arsitektur [3]. Preliminary yang didalamnya berisikan definisi dari framework arsitektur enterprise. Berikut aktivitas utama dan aktivitas pendukung 
Vol. 3, No. 2, June 2021

p-ISSN: 2656-5935 http://journal-isi.org/index.php/isi e-ISSN: 2656-4882

yang digambarkan melalui analysis value chain untuk melihat analisis lingkungan internal pada Kantor Desa Lembang.

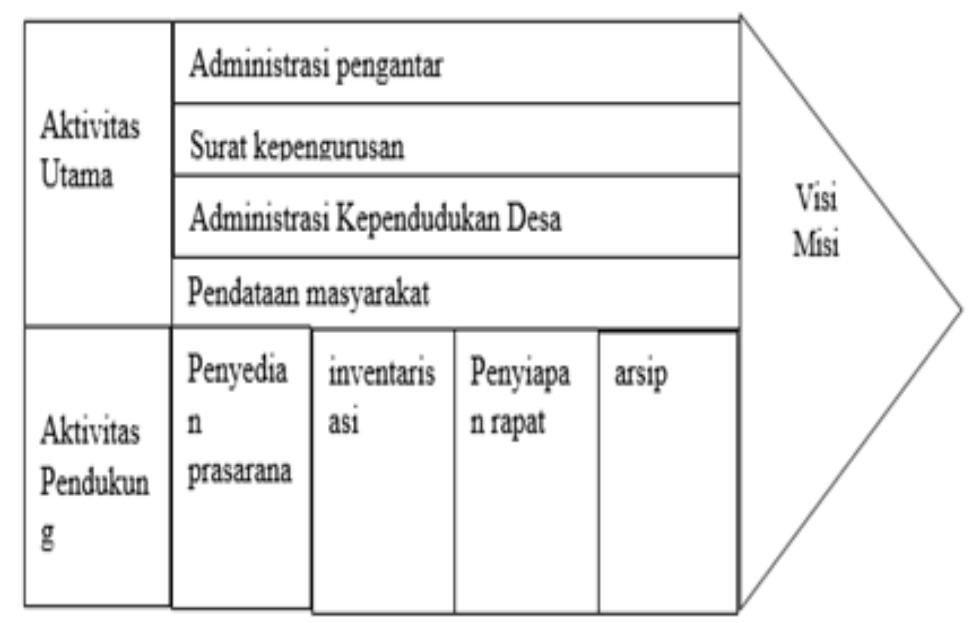

Gambar 1. Value Chain Aktivitas Utama dan Aktivitas Pendukung

Berikut Keterangan Aktivitas Utama dan Pendukung Pada Kantor Desa Lembang:

- Aktivitas Utama:

Administrasi pengantar merupakan kegiatan untuk melakukan perencanaan dalam pembangunan dan demokrasi serta peningkatan kapasitas pembangunan insfrastruktur dasar pada desa.Surat Kepengurusan merupakan kegiatan yang mengurus pindah domisili dan juga masuknya penduduknya masyarakat yang akan menetap.Administrasi Kependudukan Desa Merupakan peningkatan kapasitas keuangan untuk daerah.Pendataan Masyarakat merupakan aktivitas mendata peningkatan kerja, penanggulangan kemiskinan, pengembangan kesehatan, pemberdayaan perempuan, keluarga berencana, pengembangan pendidikan, pengembangan kualitas pemuda dan pengembangan budaya dan periwisita.

- Aktivitas Pendukung:

Penyediaan prasarana merupakan aktivitas untuk mendukung dan meyiapkan kegiatan kegiatan yang dilakukan pada desa. Inventaris merupakan kegiatan untuk mengajukan dan menyimpan sarana dan prasarana desa. P enyiapan rapat merupakan penyusunan rapat pada kegiatan desa. Arsip merupakan aktivitas yang melakukan proses penyelenggaran pemerintahan desa.

2. Phase A: Architecture Vision 
Vol. 3, No. 2, June 2021

p-ISSN: 2656-5935 http://journal-isi.org/index.php/isi

e-ISSN: 2656-4882

Pada fase ini terciptanya keragamanan sudut pandang mengenai pentingnya arsitekur enterprise itu sendiri untuk tercapainya tujuan perusahaan atau instansi. Fase ini juga merupakan inisiasi dari pengembangan arsitekur yang mengidentifikasi stakeholders, penyusunan visi, dan pengajuan untuk dapat memulai suatu pengembangan [3].

3. Phase B: Business Architecture

Pada fase ini mencakup pengembangan arsitektur bisnis dan juga menentukan model bisnis atau aktivitas bisnis serta menguraikan arsitektur bisnis dasar. Pada tahap kali ini method dan tools dapat digunakan untuk mendukung visi arsitektur yang telah disepakati [16].

4. Phase C: Information Systems Architecures

Pada fase ini merupakan tahapan dari model arsitektur data dan arsitekur aplikasi. Pada tahapan ini menekankan untuk melihat bagaimana aktivitas arsitektur sistem informasi dapat dikembangkan [5].

5. Phase D: Technology Architecture

Pada tahapan ini adalah membangun arsitekur teknologi untuk menentukan kandidat dari teknologi yang akan dibutuhkan. Pada tahapan ini juga ditentukan portofolio teknologi, katalog dan platform untuk teknologi serta meliputi perangkat keras dan lunak [6].

6. Phase E: Opportunities and Solutions

Pada fase ini akan dilakukan pengevalusian model yang akan dibangun untuk arsitektur yang ada pada saat ini dan juga tujuan mendatang. Pada tahap ini juga akan dilakukan untuk mereview gap analysis yang terdapat pada fase D. Pada Tahap ini maka untuk Kantor Desa Lembang kedepan nya bisa untuk mengikuti alur adminitrasi sistem. Pada fase ini bisa dilihat pada Gambar 2.

7. Phase F: Migration and Planning

Pada fase ini akan menganalisis resiko dan juga biaya untuk memilih proyek implementasi yang beragam untuk menjadi urutan tujuan utama. Pada tahap ini menafsirkan ketergantungan, biaya serta manfaat dari proyek yang bervariasi untuk membentuk rencana implementasi detail dan perencanaan migrasi.

8. Phase G: Implementation Governance

Pada fase ini mencakup pada pengawasan implementasi arsitektur untuk merekomendasikan proyek. Pada tahapan ini melaksanakan fungsi pengawasan yang tepat untuk memerintah deployment secara keseluruhan. 
Vol. 3, No. 2, June 2021

p-ISSN: 2656-5935 http://journal-isi.org/index.php/isi e-ISSN: 2656-4882

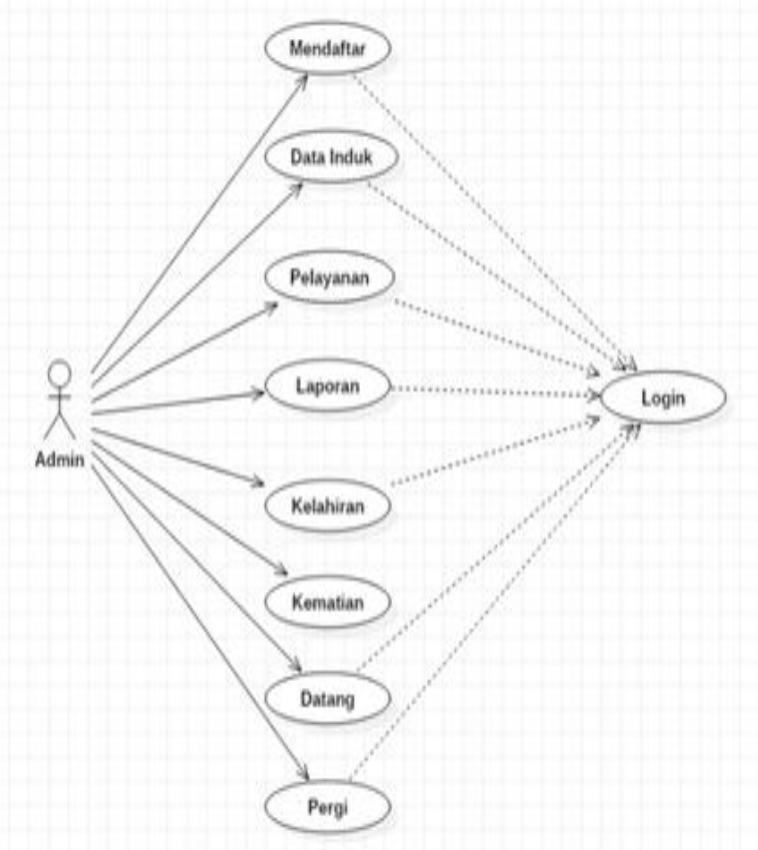

Gambar 2. Use case Alur Administrasi Penduduk

Penjelasan use case diagram pada gambar diatas:

Masyarakat datang ke Kantor Desa dengan membawa berkas yang dibutuhkan berupa KK,KTP, dan persyaratan lainnya,setelah itu menemui bagian Admin. Admin akan melakukan proses pemasukan data sesuai prosedur yaitu pendaftaran, memasukan data penduduk,melakukan layanan,laporan data yang akan dimasukan berupa data kelahiran,kematian kemudian datang dan pulang dicatat waktu dan tanggal nya setelah itu login pada sistem penyimpanan .

\section{System Information Architecture}

1. Arsitektur Data

Arsitektur Data merupakan kebutuhan untuk mendefiniskan kebutuhan data guna mendukung proses dalam bisnis. Tahapan ini juga dapat mengatur serta menentukan jenis jenis data yang layak untuk diintegrasikan dalam suatu perusahaan.

2. Arsitektur Aplikasi

Arsitektur Aplikasi untuk merencanakan sistem yang dapat diimplementasikan untuk kinerja di masa mendatang pada sistem administrasi penduduk di Kantor Desa Lembang.Arsitektur Aplikasi dapat mendukung pengelolaan aplikasi aplikasi sistem yang akan digunakan pada sebuah organisasi maupun perusahaan, 
Vol. 3, No. 2, June 2021

p-ISSN: 2656-5935 http://journal-isi.org/index.php/isi

e-ISSN: 2656-4882

sehingga dapat membantu untuk Kantor Desa Lembang agar dapat mengelola dan mengimplementasikan aplikasi nya untuk kinerja di masa depan.

\begin{tabular}{|c|l|l|}
\hline Kategori & \multicolumn{1}{|c|}{ Nama Aplikasi } & \multicolumn{1}{c|}{ Kondisi saat ini } \\
\hline \multirow{3}{*}{ Aplikasi Usulan Baru } & Sistem Administrasi & \multirow{3}{*}{$\begin{array}{c}\text { Apikasi } \\
\text { diusulkan }\end{array}$} \\
\cline { 2 - 2 } & Sistem Database & \\
\cline { 2 - 2 } & Sistem Regitrasi & \\
\cline { 2 - 2 } & DS(Data Storage) & \\
\hline
\end{tabular}

\section{KESIMPULAN}

Penelitian kali ini dapat disimpulkan bahwa hambatan untuk pendataan masyarakat yang masih tidak terarsip dengan baik dan masih membuang buang waktu sehingga tidak tepat waktu dalam pengerjaan nya. Arsitekrur enterprise dengan menggunakan Togaf adm sehingga dapat memberikan solusi dan arahan untuk dapat memanfaatkan teknologi informasi dan sistem informasi dengan maksimal agar tercapai nya kinerja yang lebih baik untuk masa mendatang sesuai dengan visi misi Pemerintahan Desa.

\section{DAFTAR PUSTAKA}

[1] A. D. M. Pada, R. Soedarso, E. Wati, and F. Devita, "Perencanaan Arsitektur Enterprise Menggunakan Metode Togaf," vol. 9, no. February 2018, pp. 153-157, 2018.

[2] R. A. Atmala and S. Ramadhani, "Rancang bangun sistem informasi pengarsipan surat menyurat," J. Teknol. Inf. dan Pendidik., vol. 11, no. 2, pp. 56-62, 2018, [Online]. Available: https://www.journal.amikmahaputra.ac.id/index.php/JIT/article/view/59 $/ 54$.

[3] D. Irmayanti and B. Permana, "Perencanaan Arsitektur Enterprise Sistem Informasi Disnakersostrans Kabupaten Purwakarta Menggunakan TOGAF," J. Teknol. Rekayasa, vol. 3, no. 1, p. 17, 2018, doi: 10.31544/jtera.v3.11.2018.17-28.

[4] J.- Leonidas and J. F. Andry, "Perancangan Enterprise Architecture Pada Pt.Gadingputra Samudra Menggunakan Framework Togaf Adm," J. Teknoinfo, vol. 14, no. 2, p. 71, 2020, doi: 10.33365/jti.v14i2.642.

[5] F. Thaib and A. R. Emanuel, "Perancangan Enterprise Architecture UNIPAS Morotai Menggunakan TOGAF ADM," Teknika, vol. 9, no. 1, pp. 1-8, 2020, doi: 10.34148/teknika.v9i1.247. 
[6] S. Rachman and D. Kurniadi, "Perencanaan Arsitektur Enterprise Sistem Informasi SMK Negeri 4 Pariaman Menggunakan TOGAF Architecture Development Method (ADM)," VoteTEKNIKA J. Vocat. ..., vol. 8, no. 2, 2020, [Online]. Available: http://ejournal.unp.ac.id/index.php/voteknika/article/view/109118.

[7] A. G. Tuwondila et al., "Perencanaan Strategis SI/ TI Pemerintahan Menggunakan the Open Group Architecture Framework ( TOGAF)," Semin. Nas. Sist. Inf. Indones., no. November, pp. 1-6, 2018.

[8] N. Rizky and A. F. Firmansyah, "PERENCANAAN ARSITEKTUR ENTERPRISE MENGGUNAKAN TOGAF ADM VERSI 9 ( Studi Kasus : Bimbel Salemba Group )," Stud. Inform. J. Sist. Inf., vol. 10, no. 1, pp. 11-20, 2017.

[9] Suryadi and J. F. Andry, "Perancangan Enterprise Architecture Mengunakan TOGAF Architecture Development Method (Studi Kasus: Yakuza Gym Jakarta Barat)," Semin. Nas. TEKNOKA, vol. 2, no. 2502, pp. 129-134, 2017, [Online]. Available: https://journal.uhamka.ac.id/index.php/teknoka/article/view/748.

[10] P. ASTIKA, "Rancangan Model Arsitektur Enterprise Menggunakan Togaf Architecture Development Method Pada Dinas Pendidikan ...," pp. 278285, 2020, [Online]. Available: https://core.ac.uk/download/pdf/300879101.pdf.

[11] E. Tan and R. Victor, "Pembuatan Enterprise Architecture untuk Gereja Jemaat Kristus Indonesia Menggunakan TOGAF Framework," J. Strateg. J. Maranatha, vol. 1, no. 2, pp. 512-526, 2019.

[12] A. Fadlil, I. Riadi, and A. Basir, "Integration of Zachman Framework and TOGAF ADM on Academic Information Systems Modeling," INTENSIF J. Ilm. Penelit. dan Penerapan Teknol. Sist. Inf., vol. 5, no. 1, pp. 72-85, 2021, doi: 10.29407/intensif.v5i1.14678.

[13] D. Y. Ratnasari and D. A. O. Turang, "Perancangan Enterprise Architecture Pada Perusahaan Bidang Jasa Menggunakan The Open Group Architecture Framework (TOGAF)," Semin. Nas. Inform., no. October, pp. 31-42, 2018, [Online]. Available: http://103.23.20.161/index.php/semnasif/article/view/2614.

[14] D. A. Prawira, Eprilyani Nur Azizah, "Perencanaan Arsitektur Enterprise Menggunakan Metode Togaf ADM Pada Puskesmas Mempawah," Semin. Nas. Sist. Inf. dan Teknol. Inf. 2018, pp. 153-157, 2018, [Online]. Available: Puskesmas, Enterprise Architecture Planning, TOGAF ADM, Blue Print, Terintegrasi\%0A1. 
[15] P. S. Teknik and I. F. Teknik, "Perencanaan Arsitektur Enterprise Menggunakan TOGAF ADM Pada Perguruan Tinggi Swasta Surabaya Untuk Memenuhi Mata Kuliah Arsitektur Enterprise Dosen Mata Kuliah Arsitektur Enterprise : Supangat, S . Kom ., M . Kom ., COBIT Disusun Oleh : Ni Kadek Eva Ang," vol. 1461800060, no. C, 2020.

[16] Y. Kustiyahningsih, "PERENCANAAN ARSITEKTUR ENTERPRISE MENGGUNAKAN METODE TOGAF ADM (STUDI KASUS : RSUD Dr.SOEGIRI LAMONGAN)," Pros. Semin. Nas. Manaj. Teknol. XVIII, pp. 1-8, 2013. 